\title{
Depicting cranial sutures: a travel into the history
}

\author{
Paolo Frassanito • Concezio Di Rocco
}

Published online: 16 December 2010

(C) Springer-Verlag 2010

\section{"the heads of men are not all alike, nor are the cranial sutures arranged the same in all" \\ Hippocrates, On Head Wounds}

Mondino de' Liuzzi (d. 1326) surely borrowed from medieval death iconography the way of illustrating anatomy, but it is interesting how his crude figure with a lateral, a posterior, and a superior view of the skull (Fig. 1) seems to anticipate the three-dimensional current neuroimaging. Despite the inaccuracy of this first attempt, the care lavished by the notable anatomist in this work proved that the interest arisen by cranial sutures comes from time immemorial. Indeed, Hippocrates (c. 460-370 BC), in the treatise On Head Wounds, described the significant variations in skull and cranial sutures morphology in detail, defining four types of sutures arrangement and the consequent head shapes [4]. However, in ancient Greece, sutures fascinated not only scientists but also historians: Herodotus (c. 484-425 BC) in his Histories, telling about the battle of Platea, where the Greeks, led by Pausania, defeated the Persian army of Mardonius, described us the exceptional finding of a skull without any suture, made up by a unique bone (Fig. 2). Later, Galen of Pergamon (130200 AD) introduced the concept of craniosynostosis by coining the term oxycephaly. In the Renaissance, Andreas Vesalius (1514-1564 AD), in his De humani corporis fabrica [6], recognized the differences in the morphology of the human skull and cranial sutures, and associated certain skull characteristics with clinicopathological entities, today identified as hydrocephalus or craniosynostosis. Although

P. Frassanito $(\bowtie) \cdot$ C. Di Rocco

Paediatric Neurosurgery, Catholic University Medical School,

Largo Agostino Gemelli, 8,

00168 Rome, Italy

e-mail: paolo.frassanito@gmail.com
Vesalius remarked the ancient ideology of a natural order, so echoing the Galenic concept of teleologic regularity, he was able to introduce an element of brilliant novelty by clearly addressing the unusual deviations of normal anatomy. However, in his study of craniology, the correlation between the missing suture and the consequent cranial deformation is not so consistent to the reality. In fact, after the first representation of normal skull with normal sutures, the second drawing represents the absence of coronal suture, although the skull is not as brachycephalic as we could expect; in the third drawing, representing the absence of the lambdoid suture, the skull is depicted in a laterolateral view, not allowing us to appreciate the posterior plagiocephaly; in the fourth drawing, an undefined laterolateral suture is represented, replacing both lambdoid and coronal sutures, a turricephalic aspect of the skull is associated; finally in the fifth drawing, although the sagittal suture is absent, the skull is not shaped in a scaphocephalic fashion (Fig. 3). In the nineteenth Century, Rudolph Virchow (1821-1902), echoing the intuition of Adolph Wilhelm Otto (1786-1845) [8], finally indicated the suture as the primary cause of craniosynostosis [9]. The subsequent step from the diagnosis to the treatment took us to the 1890, when Odilon Lannelongue (1840-1911) described a linear craniectomy intended to allow for normal brain growth. The belief that craniectomy could cure the idiocy arose initial enthusiam, driving soon to poor distinction in the selection of surgical cases between a fused suture because of microcephaly and the early closure of suture in case of craniostenosis. Consequently, the discouraging results made operative intervention rapidly falling out of favor [7]. We have to wait until the first half of the last Century, when the first radiological images of skull and its sutures were obtained [2], to see a renewed interest in craniectomies with varying results. However, the rigid 


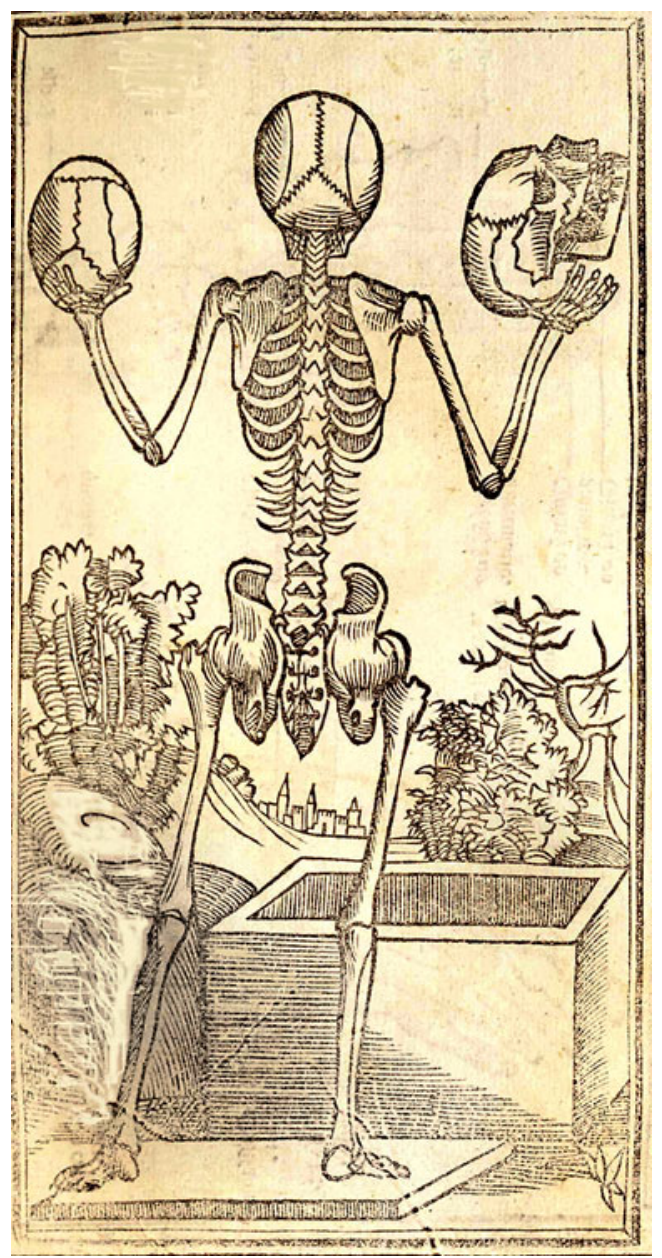

Fig. 1 This figure (used as cover illustration) shows an illustration of cranial sutures by Mondino de' Liuzzi, from J. Berengario da Carpi: Isagogae breues, perlucidae ac uberrimae in anatomiam humani corporis. Bologna, Benedictus Hector, 1523. http://www.nlm.nih.gov/ exhibition/historicalanatomies/berengario_home.html

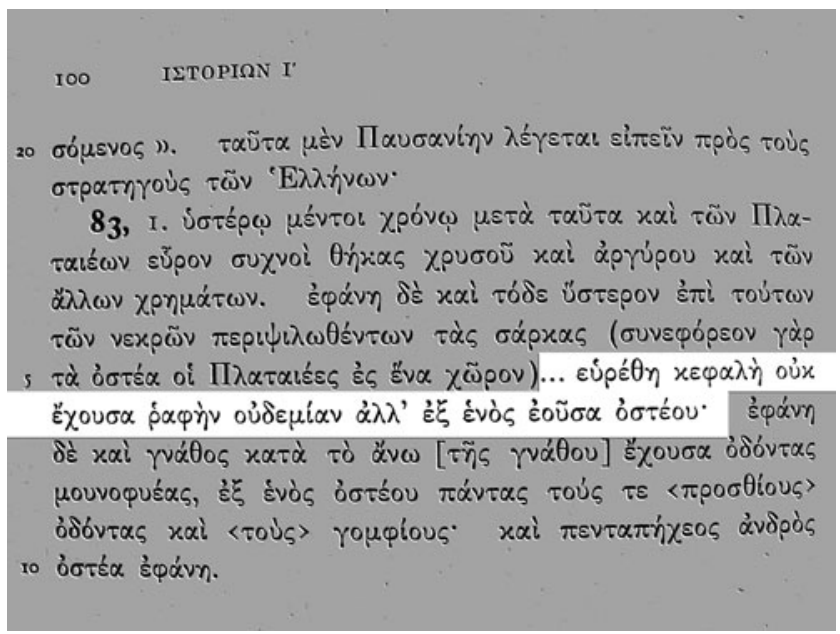

Fig. 2 Quotation from the Histories of Herodotus: "a skull without any suture, made up by a unique bone was found"

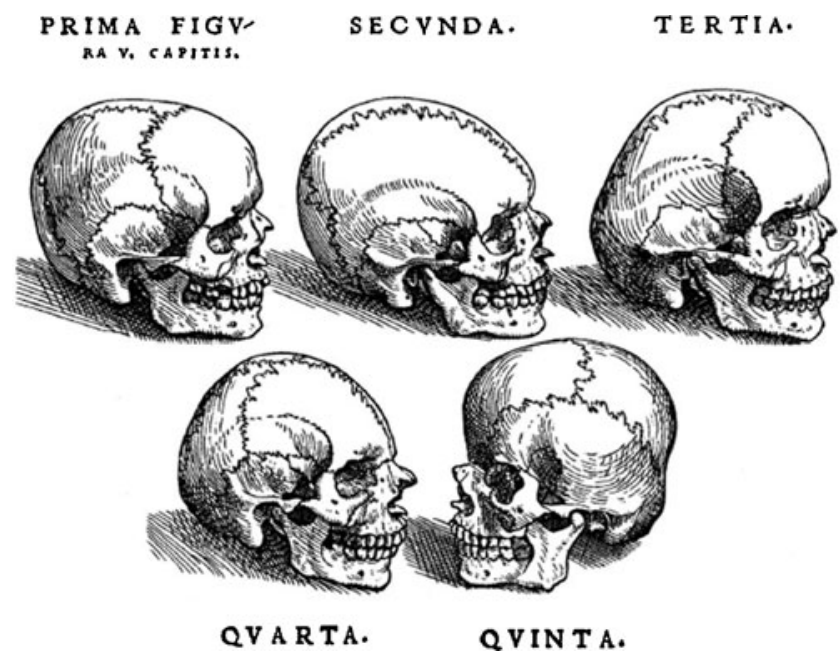

Fig. 3 Representation of variations of cranial sutures and skull morphology, from the De humani corporis fabrica of Andrea Vesalius. http:// www.nlm.nih.gov/exhibition/historicalanatomies/vesalius_home.html

two-dimensional picture of a suture became not sufficient to define it as pathological or normal in complex cases. This need of functional investigation took place in the 1970s, with skull scintigraphy aimed at depicting whether the cranial sutures were correctly working or not (Fig. 4): The initial cause of primary craniosynostosis was attributed to a localized bony fusion across a suture, revealed by bone scanning as an abnormal accumulation of bone-seeking radiopharmaceutical. The extension of the abnormal fusion process along the suture was propounded to be associated to a corresponding spread of radionuclide and the complete fusion to an uptake decrease [3]. The doubts arisen by the interpretation of bone scanning and

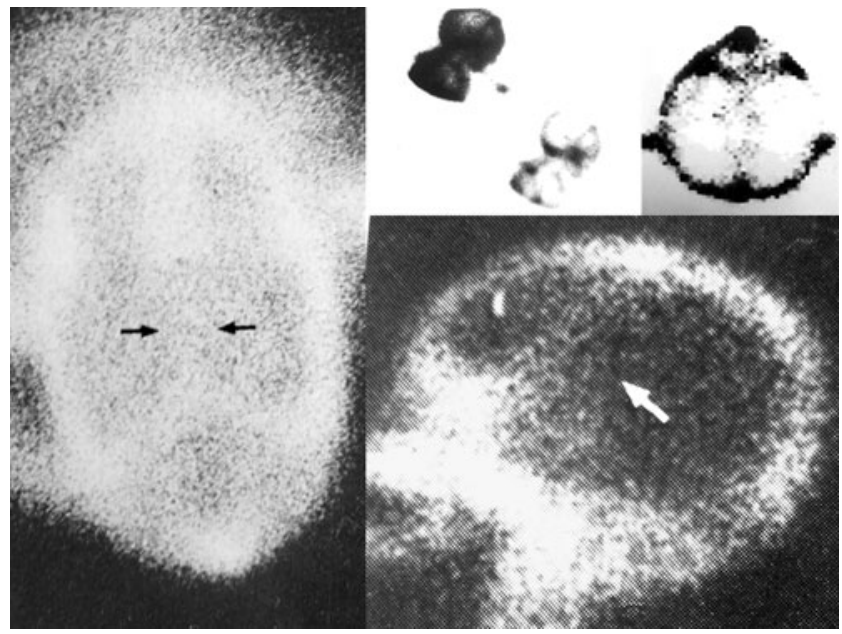

Fig. 4 Cranial bone scannings showing the abnormal uptake of radionuclides in case of early fused sutures 


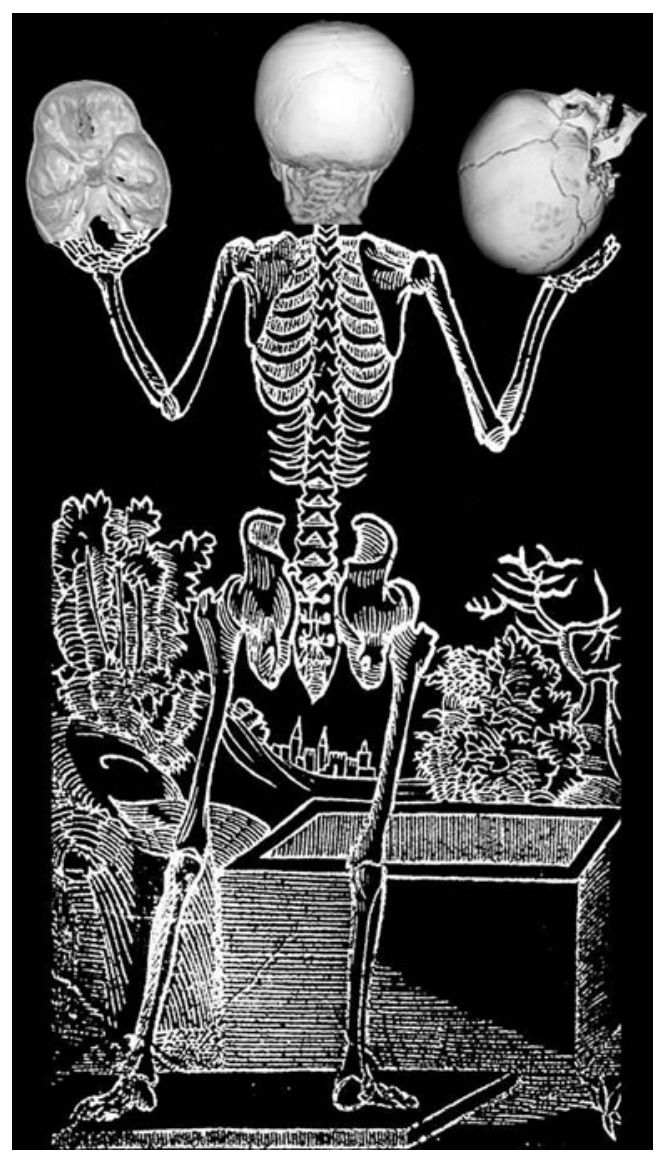

Fig. 5 Artist's rendering of the drawing by Mondino de' Liuzzi, in the light of the current neuroimaging of cranial sutures

the need of administering to patient radionuclides were passed by the advent of Computed Tomography [5] that has become the best bony anatomy illustrator. Mondino de' Liuzzi surely would envy the actual three-dimensional reconstruction of the skull, depicting skull bones and their sutures perfectly (Fig. 5). Anyway, in spite of the perfect representation of the cranial sutures which is nowadays available, the advances made in recent years in craniosynostosis knowledge have made the radiological studies of the sutures redundant in most of the cases [1].

\section{References}

1. Agrawal D, Steinbok P, Cochrane DD (2006) Diagnosis of isolated sagittal synostosis: are radiographic studies necessary? Childs Nerv Syst 22(4):375-378

2. Christensen JB, Lachman E, Bues AM (1960) A study of the roentgen appearance of cranial vault sutures: correlation with their anatomy. Am J Roentgenol Radium Ther Nucl Med 83:615-627

3. Di Rocco C, Focacci C, De Rossi G, Jannelli A, Velardi F (1979) The calvaria bone scanning in the early diagnosis of craniosynostosis. Riv Ita Ped 5:47-50

4. Dimopoulos VG, Kapsalakis IZ, Fountas KN (2007) Skull morphology and its neurosurgical implications in the Hippocratic era. Neurosurg Focus 23(1):E10

5. Furuya Y, Edwards MS, Alpers CE, Tress BM, Norman D, Ousterhout DK (1984) Computerized tomography of cranial sutures. Part 2: Abnormalities of sutures and skull deformity in craniosynostosis. J Neurosurg 61(1):59-70

6. Hast MH, Garrison DH (2000) Vesalius on the variability of the human skull: book I chapter V of De humani corporis fabrica. Clin Anat 13:311-320

7. Mittler AM, Fried AH, Epstein MH (1997) Hydrocephalus and the development of pediatric neurosurgery. In: Samuel Greenblatt H, Forcht Dagi T, Mel Epstein H (eds) A history of neurosurgery. Park Ridge, Illinois, pp 345-354

8. Otto AW (1831) A compendium of human and comparative pathological anatomy. B. Fellowes, London

9. Virchow R (1851) Über den Cretinismus, namentlich in Franken, und über pathologische Schädelformen. Verh Phys Med Ges 2:230, Würzburg 